\title{
PRODUÇÃO DE RESINA TROCADORA DE ÍONS A PARTIR DE POLIETILENO RETICULADO
}

\author{
C. F. CASTRO ${ }^{1}$, L. C. G. A. PANZARINI ${ }^{1, *}$, M. S. FERRARA ${ }^{1}$, M. P. MARQUES ${ }^{1}$, \\ M. F. F. ALMEIDA ${ }^{1}$, T. M. B. MACHADO ${ }^{1}$, Y. S. CAPELLE ${ }^{1}$ \\ ${ }^{1}$ Centro Universitário da FEI, Departamento de Engenharia Química \\ *E-mail: luzarini@fei.edu.br
}

\begin{abstract}
RESUMO: Entre os termofixos existentes no mercado, encontra-se o polietileno reticulado (PEX), que é utilizado no encapsulamento de fios de alta tensão. Nesse processo, uma grande quantidade de resíduos é gerada e descartada, onerando a produção e prejudicando o meio ambiente. Desse modo, este trabalho propôs a modificação química do PEX por meio de reações de sulfonação, que consistem na introdução de grupos $\mathrm{SO}_{3} \mathrm{H}$ em sua estrutura. Estudou-se a influência da pré-irradiação em micro-ondas, do tempo de reação e da concentração de $\mathrm{SO}_{3}$ livre no ácido sulfúrico fumegante por FTIR-ATR, DRX e ICP. Pelos resultados obtidos verificou-se que $\mathrm{PEX}-\mathrm{SO}_{3} \mathrm{H}$ pode ser classificado como uma resina fortemente catiônica. Os melhores resultados foram obtidos com 30 minutos de reação e $65 \%$ de $\mathrm{SO}_{3}$ livre sem pré-irradiação em micro-ondas. Apesar da avaliação econômica não ter sido satisfatória, esse estudo abre novas possibilidades para a reciclagem de termofixos.
\end{abstract}

PALAVRAS-CHAVE: polietileno reticulado; PEX; reciclagem; sulfonação; resina trocadora de íons.

\section{INTRODUÇÃO}

Nos dias atuais, a preocupação com o aquecimento global e impactos ambientais cresce cada vez mais, levando o homem à encontrar formas alternativas e sustentáveis dentro da indústria. Um grande problema é a quantidade de resíduos plásticos acumulados, sejam termoplásticos ou termofixos, uma vez que estes demoram mais de cem anos para se decompor, o que causa um impacto enorme ao meio ambiente.

Um dos polímeros mais utilizados na indústria é o polietileno, representando $33 \%$ da produção dos Estados Unidos, a qual chegou a cinquenta mil toneladas em 2005 (LOKENSGARD, 2013). O consumo mundial desse polímero chegou a sessenta e quatro milhões de toneladas em 2009 (ISAYEV; HUANG, 2014). Em 2011, o Brasil reciclou cerca de 21,7\% dos plásticos, o que representa 953 mil toneladas por ano (Compromisso Empresarial Para Reciclagem- CEMPRE, 2016). Todos esses materiais são termoplásticos, ou seja, amolecem com determinada temperatura, dessa forma é possível reciclá-los por um processo físico (LOKENSGARD, 2013). Entretanto, existe uma deficiência em reciclar termofixos, como por exemplo, o polietileno reticulado (PEX), justamente por estes não 
amolecerem perante à temperatura. Estes materiais geralmente são incinerados, liberando gases tóxicos à atmosfera, ou enterrados em aterros, o que causa grandes danos para o meio ambiente. Existem vários estudos que visam a reciclagem do polietileno reticulado, utilizando diferentes métodos, como por exemplo, a modificação estrutural por inserção de grupos funcionais, que tem como objetivo modificar a estrutura do polímero para que esse possa ser utilizado como um novo material em uma aplicação diferente da anterior. (ISAYEV; HUANG, 2014).

O objetivo deste trabalho foi a modificação química de resíduos de PEX, gerados por empresas fornecedoras de cabos de alta tensão, visando sua possível utilização como resina trocadora de íons. Para isso, foi realizada a sulfonação direta do PEX com ácido sulfúrico fumegante, além da sulfonação após a ativação do PEX em micro-ondas. Para isso, amostras de PEX não sulfonado e sulfonado foram caracterizadas quanto ao grau de reticulação por meio das frações solúveis (sol) e insolúveis (gel), FTIR usando-se o acessório ATR (atenuação total reflexível), difração de raios-X (DRX) e ICP (Inductively Coupled Plasma).

\section{METODOLOGIA}

\subsection{Caracterização da Matéria Prima (PEX)}

Amostras de PEX não sulfonado foram moídas até obter-se um pó com mesh 35. Essas amostras foram, então, lavadas com sabão neutro e enxaguadas abundantemente com água deionizada. A seguir as amostras foram secas em estufa a $100{ }^{\circ} \mathrm{C}$ até massa constante e guardadas em dessecador a vácuo para caracterizações futuras.

A caracterização do PEX não sulfonado foi realizada por meio da determinação do grau de reticulação do polímero, avaliando-se as frações sol e gel, bem como o grau de intumescimento das amostras, conforme duas metodologias (A e C) retiradas da norma ASTM (American Society for Testing and Materials) D2765-11 (ASTM, 2006).

O método A consiste em submeter a amostra à um refluxo em extrator Soxhlet por 12 horas, a fim de obter a fração solúvel do polímero, que permite relacionar a massa da amostra, após a extração, com a massa inicial da mesma, possibilitando a determinação da fração insolúvel, ou seja a fração gel, que corresponde à fração reticulada. $\mathrm{O}$ método $\mathrm{C}$ consiste na determinação da razão de intumescimento da amostra por meio de sua imersão em xileno por 24 horas. Quanto menor a razão de intumescimento maior o grau de reticulação da amostra.

\subsection{Sulfonação do PEX}

Os procedimentos adotados neste trabalho são uma adaptação do artigo de Zaidi (2003), sendo realizados em duplicatas. O polímero foi previamente lavado e pulverizado, obtendo-se um pó de mesh 35 . Em seguida, o polímero foi seco em estufa a $100^{\circ} \mathrm{C}$ até massa constante. Amostras do polímero seco foram pesados em balança analítica de modo a obterse $0,300 \mathrm{~g} \pm 0,001 \mathrm{~g}$ do material. Essas amostras foram transferidas para um Erlenmeyer de $500 \mathrm{~mL}$ e levadas para uma capela com exaustão adequada. Em seguida, adicionou-se, gota a gota, $20 \mathrm{~mL}$ de ácido sulfúrico fumegante $65 \%$, a cada amostra com o auxílio de uma pipeta. 
As misturas foram aquecidas a $90^{\circ} \mathrm{C}$ sob agitação magnética durante períodos diferentes, sendo estes de 30 e $50 \mathrm{~min}$, respectivamente. Após o tempo de reação, as misturas foram resfriadas à temperatura ambiente. Em seguida, as misturas foram transferidas para béqueres contendo $500 \mathrm{~mL}$ de água gelada e os sistemas foram mantidos sob agitação mecânica a 220 rpm por 60 minutos. Após esse período, as misturas foram mantidas em repouso por 12 horas. A seguir, as misturas foram filtradas em funil de Büchner, lavadas com água deionizada até $\mathrm{pH} 5,0$ e secas em estufa à vácuo a $100^{\circ} \mathrm{C}$ até massa constante. Após a secagem, as amostras foram transferidas para um porta amostras e armazenadas em dessecador à vácuo para posterior caracterização. (ZAIDI, 2003).

O mesmo procedimento foi repetido, variando-se as concentrações de SO3 livre, a partir da diluição do ácido sulfúrico fumegante, de modo a obter-se concentrações de $10 \%$, $20 \%, 30 \%, 40 \%, 50 \%$ e $60 \%$. Para cada concentração estudada, variou-se o tempo de reação de 10 em 10 minutos até 60 minutos.

Para avaliar o efeito das micro-ondas nesse processo de sulfonação do PEX, amostras do polímero foram pré-irradias por 2 minutos em um micro-ondas, modelo MDS-2000, a uma potência nominal de 700 Watts, antes da adição do ácido sulfúrico. Os passos seguintes seguiram o mesmo procedimento descrito anteriormente.

\subsection{Caracterização do PEX Após Sulfonação}

O polímero obtido em cada procedimento proposto foi avaliado em função da variação na cristalinidade, das alterações em grupos funcionais específicos e por fim, da capacidade trocadora de íons da resina sulfonada técnicas.

Difração de raios-X (DRX): A técnica de caracterização por difração de raios-X foi realizada em difratômetro de Raio X, Modelo XRD-7000, Shimadzu, utilizando-se 5s para cada passo de contagem de tempo e uma taxa de $1^{\circ} / \mathrm{min}$ na escala de $5^{\circ}$ a $40^{\circ}$ em $2 \theta$. O índice de cristalinidade foi calculado pelo método da área, sendo a cristalinidade calculada pela razão entre a área total das regiões cristalinas e a área total do material (amorfo e cristalino) x 100 .

Capacidade trocadora de íons: Foram realizados testes em padrões de água dura (contendo íons de $\mathrm{Ca} 2+$ ) a fim de avaliar a capacidade trocadora de íons da resina. Para isso, foi usado o equipamento ICP (Inductively Coupled Plasma).

Espectroscopia de infravermelho FTIR-ATR: A espectroscopia de absorção na região do infravermelho foi usada para confirmar a presença dos grupos sulfônicos a partir de variações nos modos vibracionais decorrentes de ligações $\mathrm{C}-\mathrm{S}, \mathrm{S}-\mathrm{O}$ e $\mathrm{O}-\mathrm{H}$ das amostras com concentrações de 10\%, 20\%, 30\%, 40\%, 50\%, 60\% nos tempos de 10, 20, 30, 40, 50 e 60 minutos e para $65 \%$ nos tempos de 30 e 50 minutos, além do PEX não sulfonado. A leitura da absorbância das amostras foi realizada em um espectrofotômetro FTIR Thermo Scientific Class I Nicolet 6700, utilizando-se o acessório de Atenuação Total Reflexiva (ATR). 


\section{RESULTADOS E DISCUSSÕES}

\subsection{Determinação do grau de reticulação do PEX}

Metodologia A - ASTM D2765-11: A partir da caracterização do PEX pela metodologia A foi possível calcular a fração insolúvel (teor de gel) do polímero, sendo esta, caracterizada pela porcentagem extraída. Os experimentos foram realizados em duplicatas, e a partir destes, chegou-se em um valor médio de teor de gel de $64,386 \%$, o que indica que o polímero possui um grau de reticulação elevado, uma vez que quanto maior essa porcentagem, mais reticulado é o material. A porcentagem extraída foi de $35,6 \%$, que é referente à parte solúvel do PEX, a qual pode ter sido influenciada pela quantidade de cargas e aditivos contidos na formulação do polímero.

Metodologia C - ASTM D2765-11: A partir desta metodologia foi possível calcular a razão de inchamento (intumescimento) do polímero. Os experimentos também foram realizados em duplicatas, e a partir destes, foi possível chegar em uma razão de inchamento média de 2,940, que indica que o polímero após a imersão no xileno por 24 horas apresenta uma massa cerca de 3 vezes maior que a inicial. Vários fatores podem influenciar na capacidade de intumescimento de um polímero reticulado, sendo um deles a quantidade de cargas e aditivos contidos no material e também, a fração não reticulada. Quanto mais reticulado é o polímero menor é a sua razão de intumescimento.

\subsection{Caracterização por FTIR-ATR}

Observou-se que as sulfonações realizadas com tempo de reação de 30 minutos em diferentes concentrações de $\mathrm{SO}_{3}$ livre $(10 \%, 20 \%, 30 \%, 40 \%$ e $50 \%)$ não apresentaram variações significativas nas bandas características das ligações O-H, S-O e C-S. A única concentração de ácido sulfúrico fumegante que apresentou variações significativas em seus resultados foi o de $65 \%$, realizada no tempo de 30 minutos. Na Figura 1 são comparados alguns espectros, os de concentrações de $10 \%, 40 \%$ e $65 \%$ - 30 minutos. Os espectros de $20 \%, 30 \%$ e $50 \%$ - 30 minutos apresentam o mesmo comportamento dos espectros de $10 \%$ e $40 \%$ - 30 minutos.

Visto que a concentração de $65 \%$ foi a única que apresentou resultados significativos, verificou-se a influência da pré-irradiação em micro-ondas por 2 minutos, seguido da sulfonação nos tempos de 20, 30 e 40 minutos. A Figura 2 apresenta a comparação entre os espectros para a concentração de 65\% - 30 minutos sem (SMO) e com (MO) pré irradiação em micro-ondas, respectivamente. As amostras nos tempos de 20 e 40 minutos não apresentaram diferenças significativas. 


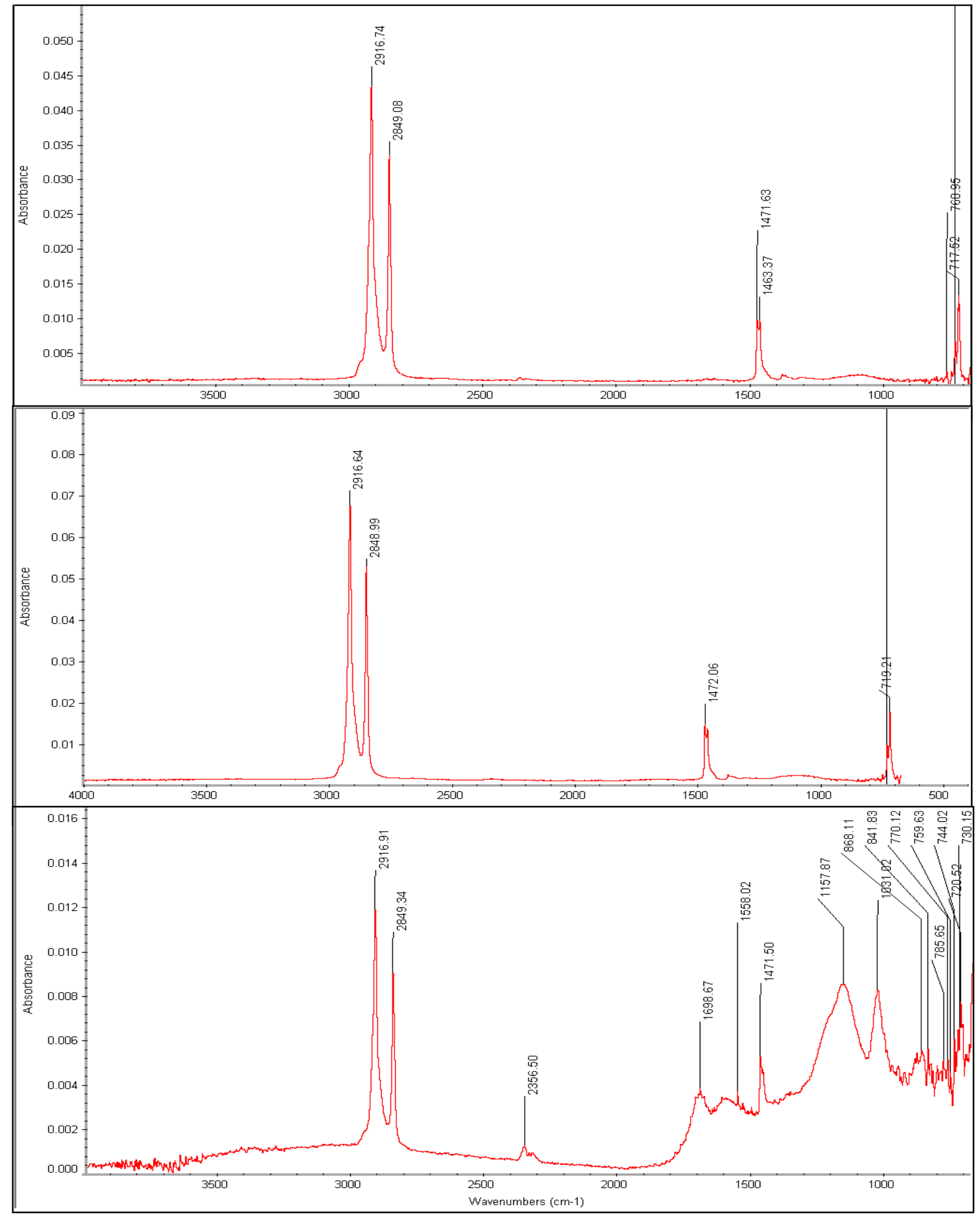

Figura 1- Sobreposição dos espectros FTIR-ATR para concentrações 10\%, 40\% e 65\% em 30 minutos respectivamente. 


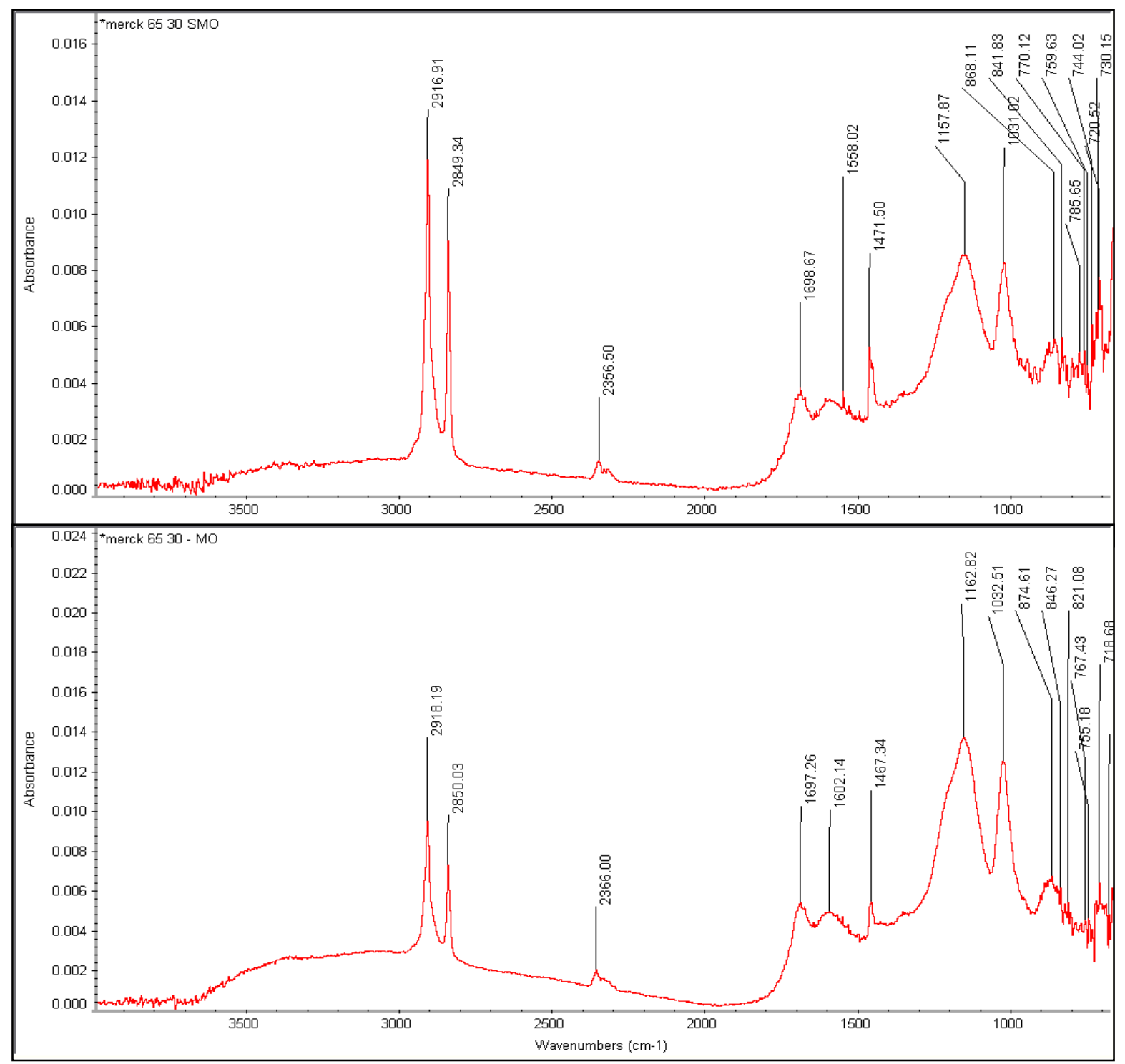

Figura 2 - Resumo dos espectros de concentração de 65\% no tempo de 30 minutos sem (SMO) e com (MO) pré irradiação de micro-ondas respectivamente.

Kaneko et al, 2003 apresentou resultados FTIR para a sulfonação do PEBD, Tabela 1. A comparação com os resultados obtidos neste trabalho mostra um padrão compatível com as reações de sulfonação, Tabela 2.

Tabela 1 - Resultados obtidos do PEBD sulfonado, por Kaneko et al. (2003).

\begin{tabular}{cc}
\hline Banda & Absorção $\left(\mathbf{c m}^{-1}\right)$ \\
\hline $\mathrm{S}-\mathrm{O}-\mathrm{C}$ & 900 \\
$\mathrm{O}=\mathrm{S}=\mathrm{O}$ & 1040 \\
$\mathrm{O}=\mathrm{S}=\mathrm{O}$ & $1080-1250$ \\
$\mathrm{C}=\mathrm{C}$ & $1600-1700$ \\
$\mathrm{C}=\mathrm{O}$ & $1680-1750$ \\
\hline
\end{tabular}


Tabela 2 - Resultados obtidos do PEX sulfonado, neste trabalho.

\begin{tabular}{cc}
\hline Banda & Absorção $\left(\mathbf{c m}^{-1}\right)$ \\
\hline $\mathrm{S}-\mathrm{O}-\mathrm{C}$ & $849-886$ \\
$\mathrm{O}=\mathrm{S}=\mathrm{O}$ & $1034 / 1088-1235$ \\
$\mathrm{C}=\mathrm{C}$ & $1600-1700$ \\
$\mathrm{C}=\mathrm{O}$ & 1700 \\
\hline
\end{tabular}

\subsection{Caracterização Via DRX}

Foram realizados ensaios de caracterização via DRX para as amostras sulfonadas com ácido sulfúrico fumegante $65 \%$ para os tempos 20,30 e 40 minutos com e sem pré-irradiação em micro-ondas, Figura 3.

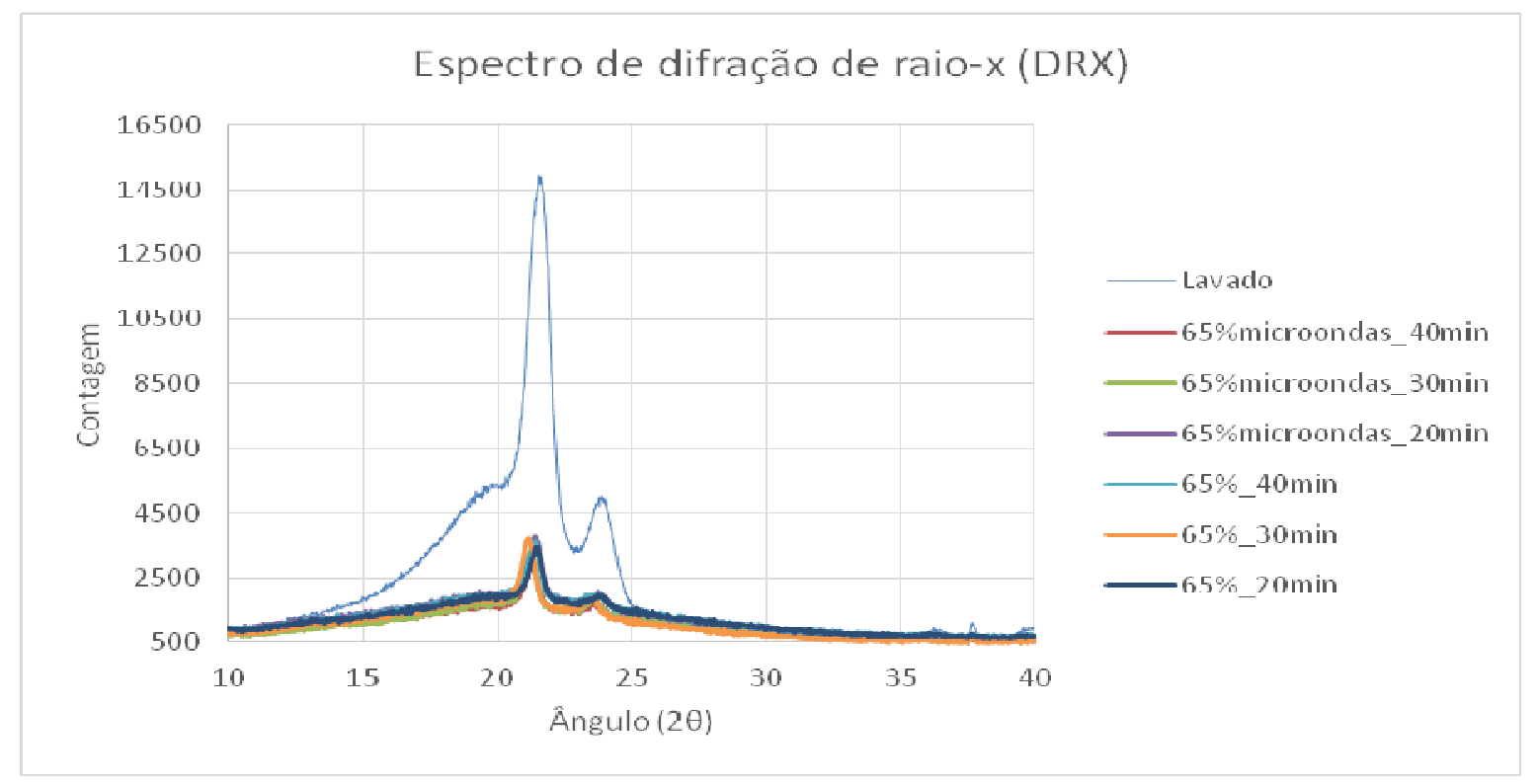

Figura 3 - Espectro de DRX para todas as amostras sulfonadas e polímero sem tratamento (lavado).

As amostras apresentaram uma sequência de picos relevantes entre 20 a 25 graus, que se referem à ligação $\mathrm{CH}_{2}$. Observou-se diminuição na cristalinidade para todas as amostras sulfonadas, não havendo influência significativa do tempo de reação.

A diminuição na cristalinidade do polímero pode ser explicada devido ao aumento do volume livre decorrente da inserção dos grupos sulfônicos, que diminuem as interações secundárias entre as cadeias poliméricas.

Pela ampliação do gráfico para as amostras sulfonadas, Figura 4, é possível verificar que os resultados mais significativos foram observados para as amostras pré-irradiadas em micro-ondas e sulfonadas com concentrações de $\mathrm{SO}_{3}$ de $65 \%$ em tempos de reação de 30 e 40 minutos. 


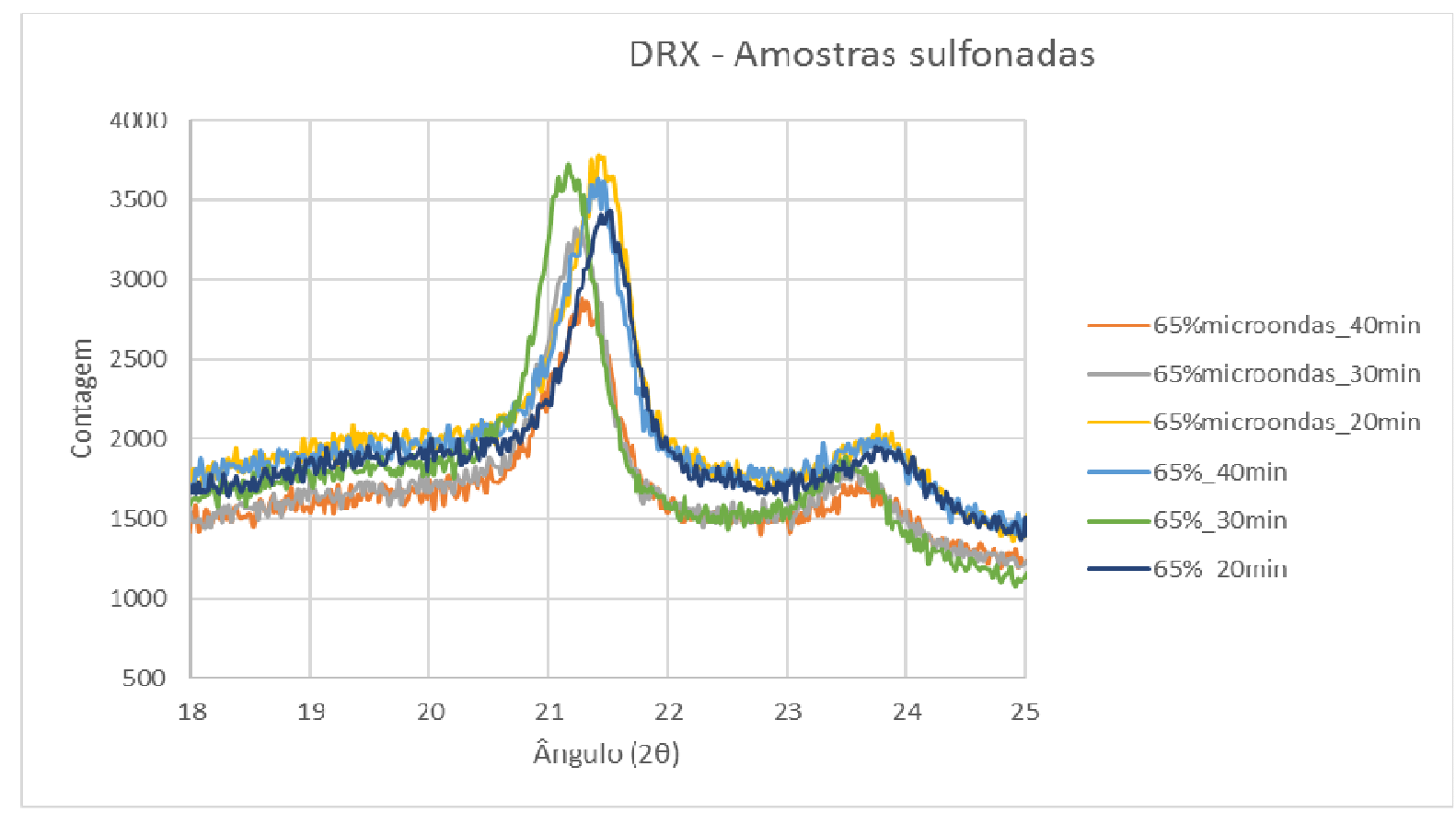

Figura 4 - Ampliação dos espectros de DRX dos polímeros sulfonados.

\subsection{Caracterização Via ICP}

Os ensaios via ICP foram realizados para as amostras de água dura tratadas com as resinas sulfonadas em ácido sulfúrico fumegante 65\% nos tempos de 20, 30 e 40 minutos com a pré-irradiação em micro-ondas, Tabela 3, e sem a pré-irradiação de micro-ondas, Tabela 4, para verificar o potencial de absorção de íons de cálcio pela resina trocadora de íons, a partir de uma solução padrão contendo $39,7 \mathrm{mg} / \mathrm{L}$ de cálcio.

Tabela 3 - Resultados para a concentração de cálcio nas amostras de água dura tratadas com as resinas pré-irradiadas em micro-ondas

\begin{tabular}{cc}
\hline $\begin{array}{c}\text { Tempo de reação com o Ácido Sulfúrico } \\
\text { Fumegante (min) }\end{array}$ & $\begin{array}{c}\text { Solução CaCO3 após imersão do } \\
\text { polímero [Ca] (mg/L) }\end{array}$ \\
\hline 20 & 1,51 \\
30 & 1,67 \\
40 & 2,28 \\
\hline
\end{tabular}

Tabela 4 - Resultados para a concentração de cálcio nas amostras de água dura tratadas com as resinas sulfonadas sem pré-irradiação em micro-ondas.

\begin{tabular}{cc}
\hline $\begin{array}{c}\text { Tempo de reação com o Ácido Sulfúrico } \\
\text { Fumegante (min) }\end{array}$ & $\begin{array}{c}\text { Solução CaCO3 após imersão do } \\
\text { polímero [Ca] }(\mathbf{m g} / \mathbf{L})\end{array}$ \\
\hline 20 & 3,01 \\
30 & 1,19 \\
40 & 2,1 \\
\hline
\end{tabular}

Pelos resultados obtidos verifica-se que a amostra com a maior capacidade trocadora de íons foi a tratada com ácido sulfúrico fumegante $65 \%$, no tempo de reação de 30 minutos, 
sem pré-irradiação em micro-ondas, uma vez que foi a solução que apresentou a menor concentração final de cálcio, com um valor de $1,19 \mathrm{mg} / \mathrm{L}$.

\subsection{Avaliação da Eficiência da Resina e da Viabilidade Econômica}

Com base nos resultados obtidos por ICP, foi possível calcular a eficiência da resina trocadora de íons. Considerando a concentração inicial de $\mathrm{Ca}^{2+}$ na água dura de $39,7 \mathrm{mg} / \mathrm{L}$ e a concentração final de $1,19 \mathrm{mg} / \mathrm{L}$, obteve-se uma eficiência de $97 \%$, o que justifica sua utilização para o tratamento de águas duras.

Para avaliar a viabilidade econômica considerou-se a massa de resina gerada por litro de ácido sulfúrico fumegante utilizado. Para produzir um litro da resina sulfonada foram necessários $127 \mathrm{~kg}$ de ácido sulfúrico fumegante. Dessa forma, considerando que não houve custo para aquisição da resina e a cotação atualizada para o ácido sulfúrico fumegante $65 \%$, chega-se a um valor de R $\$ 219,08 / \mathrm{L}$ de resina. Esse valor está muito distante dos praticados comercialmente para resinas de troca iônica, cujo preço varia entre $\mathrm{R} \$ 19,96 / \mathrm{L}$ e $\mathrm{R} \$ 31,96 / \mathrm{L}$. Mesmo assim, é preciso ressaltar a "importância sustentável" de reciclar esses polímeros. Neste trabalho, não foram consideradas informações quanto ao valor que será agregado ao resíduo das empresas para negociação com os recicladores, ou quanto à reutilização do ácido sulfúrico fumegante em processos subsequentes.

\section{CONCLUSÃO}

Com o resultado das duas metodologias de caracterização realizadas, baseadas na NORMA ASTM D2765-11, e nas metodologias de sulfonação e caracterizações via FTIRATR, DRX e ICP e nos cálculos de eficiência e viabilidade econômica, é possível confirmar que:

- O PEX utilizado apresenta grau de reticulação de 64,86\%;

- O PEX utilizado foi reticulado através do método com silano, a partir de grupos trimetoxi-silano vinilicos;

- O PEX apresenta volume livre condizente com estruturas saturadas e não reticuladas, o que pôde ser confirmado pela presença de bandas características de $\mathrm{CH}_{3}$ nos espectros FTIR;

- A sulfonação do PEX diminuiu a cristalinidade do polímero em todas as condições estudadas, o que pode ser atribuído tanto à inserção de grupos sulfônicos na cadeia polimérica, quanto à possível degradação de sítios reticulados;

- A pré-irradiação com microondas mostrou-se mais efetiva, quanto à capacidade trocadora de íons $\mathrm{Ca}^{2+}$ da resina sulfonada, para um tempo de reação de 20 minutos. Os valores obtidos, entretanto, são inferiores àqueles observados na ausência de microondas;

- O tempo de pré-irradiação estudado (dois minutos), mostrou-se pouco efetivo para a modificação do PEX em estudo; 
- O uso de microondas como agente de ativação para as reações de sulfonação pode ser mais efetivo se estudado em outros intervalos de tempo, o que não foi possível neste projeto;

- A melhor condição de sulfonação do PEX apresentada teve tempo de reação igual a 30 minutos em Ácido Sulfúrico Fumegante 65\%, na ausência de microondas;

- A Eficiência de $97 \%$ mostra que a resina obtida poderia facilmente ser utilizada para retirar a dureza da água utilizada em aplicações industriais;

- O Preço do produto de $\mathrm{R} \$ 219,08$ /L mostra que no momento não seria uma opção economicamente viável, porém abrem-se novas ideias e novas rotas a serem traçadas para que futuramente se chegue a uma metodologia que torne esse produto viável.

\section{AGRADECIMENTOS}

Ao Centro Universitário FEI pelo suporte para o desenvolvimento do trabalho.

\section{REFERÊNCIAS}

AMERICAN SOCIETY FOR TESTING AND MATERIALS - ASTM. D22765-11: Standard Test Methods for Determination of Gel Content and Swell Ratio of Crosslinked Ethylene Plastics. West Conshohocken, Pa, USA: Astm International, 2006.

COMPROMISSO EMPRESARIAL PARA RECICLAGEM - CEMPRE. PLÁSTICOS. Disponível em: <http://cempre.org.br/artigo-publicacao/ficha-tecnica/id/4/plasticos>. Acesso em: 05 mar. 2016.

ISAYEV, Avraam I.; HUANG, Keyuan. Recycling peroxide-crosslinked polyethylene. 2014. Disponível em:< http://www.4spepro.org/view. php?article=005351-2014-03-18 > . Acesso em 13 set. 2016

KANEKO, Masashi et al. Study of Sulfonation Mechanism of Low-Density Polyethylene Films with Fuming Sulfuric Acid. Polymer Engineering And Science. Volume 43, p. 2436-2442. 14 jul. 2003.

LOKENSGARD, Erik. Plásticos Industriais: Teoria e Aplicações. 5. ed.: Cengage Learning, 2013.

ZAIDI, S.m. Javaid. POLYMER SULFONATION - A VERSATILE ROUTE TO PREPARE PROTON-CONDUCTING MEMBRANE MATERIAL FOR ADVANCED TECHNOLOGIES. The Arabian Journal For Science And Engineering, Dhahran Saudi Arabia, v. 28, n. 2, p.183-194, out. 2003. 


\title{
ION-EXCHANGE RESIN FROM CROSSLINKED POL YETHYLENE
}

\author{
C. F. CASTRO ${ }^{1}$, L. C. G. A. PANZARINI ${ }^{1, *}$, M. S. FERRARA ${ }^{1}$, M. P. MARQUES ${ }^{1}$, \\ M. F. F. ALMEIDA ${ }^{1}$, T. M. B. MACHADO ${ }^{1}$, Y. S. CAPELLE ${ }^{1}$ \\ ${ }^{1}$ FEI University, Department of Chemical Engineering \\ *E-mail: luzarini@fei.edu.br
}

\begin{abstract}
Among thermoset polymers on the market, there is a crosslinked polyethylene (PEX), which is used for high voltage cable encapsulation. A large amount of waste is generate and disposed in this process, causing burden of production and environmental hazards. Thus, this project has proposed PEX chemical modification by sulfonation reactions, which consists in the insertion of SO3H groups in its structure. The Influences of the microwaves pre-irradiation, time of reaction and concentration of free $\mathrm{SO}_{3}$ in sulfuric acid were studied by FTIR-ATR, DRX and ICP. As a result, PEX-SO $\mathrm{O}_{3} \mathrm{H}$ presented to be a strong cationic resin. The best results were that obtained in 30-minute reaction and sulfonic acid with $65 \%$ of free $\mathrm{SO}_{3}$. The microwave pre-irradiation was not effectiveness in this process. The $\mathrm{PEX}-\mathrm{SO}_{3} \mathrm{H}$ obtained in this work shows at about $97 \%$ of efficiency in remove $\mathrm{Ca}^{2+}$ from water, which proves it can be used on water treatment. Although cost-benefit analysis was not satisfactory, this study expands new possibilities for thermoset recycling.
\end{abstract}

KEYWORDS: Crosslinked polyethylene; PEX; Sulfonation; Ion-exchange resin. 